\title{
Suitable friction sliding materials for base isolation of masonry buildings
}

\author{
Radhikesh P. Nanda ${ }^{\mathrm{a}, *}$, Pankaj Agarwal ${ }^{\mathrm{b}}$ and Manish Shrikhande ${ }^{\mathrm{b}}$ \\ ${ }^{a}$ Department of Civil Engineering, National Institute of Technology Durgapur, Durgapur, India \\ ${ }^{\mathrm{b}}$ Department of Earthquake Engineering, Indian Institute of Technology Roorkee, Roorkee, India
}

Received 30 May 2010

Revised 15 November 2011

\begin{abstract}
A feasibility study of friction base isolation system for seismic protection has been performed. Four different sliding interfaces, namely, green marble/High Density Poly Ethylene (HDPE), green marble/green marble, green marble/geosynthetic, and green marble/ rubber layers have been studied through experimental and analytical investigations. The experimental investigations show that the coefficient of friction values of these interfaces lies in the desirable range for seismic protection, i.e., 0.05 to 0.15 . The analytical investigation reveals that most of these sliding interfaces are effective in reducing spectral accelerations up to $50 \%$ and the sliding displacement is restricted within plinth projection of $75 \mathrm{~mm}$ (3 in). Green marble and geosynthetic are found to be better alternatives for use in friction isolation system with equal effectiveness of energy dissipation and limiting the earthquake energy transmission to super structure during strong earthquake leading to a low cost, durable solution for earthquake protection of masonry buildings.
\end{abstract}

Keywords: Base isolation, masonry buildings, pure friction, static and dynamic friction test

\section{Introduction}

Masonry buildings form a major constituent of building stock in many parts of the world. There are innumerable advantages of masonry construction over both types of contemporary construction, i.e., reinforced concrete as well as steel, such as, thermal insulation, acoustics, easy and inexpensive repair, use of locally available materials, need of less skilled labour, less engineering intervention, etc. However, poor seismic withstand capacity is a major hindrance for its use in seismically active regions. A survey of earthquake affected areas in several past earthquakes in India (Bhuj, 2001; Chamoli, 1999; Jabalpur, 1997; Killari, 1993; Uttarkashi, 1991; and Bihar-Nepal, 1988) has clearly demonstrated that the collapse of low strength masonry buildings is primarily responsible for the loss of lives.

The quest for improving the seismic behaviour of masonry structures has led to several recommendations for earthquake resistant features in various codes of practice. The recommendations are based on following basic concepts: (i) need of integral action; (ii) strong and ductile connections between walls, roof elements and foundation; (iii) improvement in strength for out-of-plane bending; (iv) strengthening of weaker sections by steel, timber, or reinforced concrete; and (v) improving the strength of mortar, quality of construction and insertion of bonding elements. Traditional methods of improving the seismic behaviour of masonry constructions with seismic bands primarily aim at preventing the collapse while sustaining some structural damage [13]. Due to inherent poor strength and ductility of masonry construction the desired earthquake resistant features can be incorporated only in a limited way to resist earthquake forces. The limitations of such measures have led to the search for alternative non-

\footnotetext{
*Corresponding author: Radhikesh P. Nanda, Department of Civil Engineering, National Institute of Technology Durgapur, Durgapur-713209, India. Tel.: +91 343 2546397; Fax: +91343 2547375; E-mail: rpnanda2002@yahoo.co.in.
} 
conventional techniques that are economically viable as well as adaptable to the conventional construction practices. Distributed base isolation [11] technique of pure friction (P-F) sliding system is one of the feasible solutions that can be used in practice. Distributed base isolator in the form of long strips would have a distinct advantage for seismic response reduction in masonry structures. In P-F isolation system a smooth layer is introduced at plinth level, on which the superstructure simply rests and is free to slide except for friction resistance. Until the frictional resistance is not overcome, super-structure may continue to move together with the foundation, behaving as an elastic structure.

\section{Earlier works}

The first proposal for a P-F base isolation system was made by an English physician Calantarients [7]. He suggested uncoupling of structure from the foundation by a layer of talc and sand as a means for seismic protection. Arya [1] and Qamaruddin et al. [10] proposed a sliding joint concept which consists of decoupling the building at the plinth level, by providing a smooth finished layer of cement sand mortar over the lower plinth wall and Mobil ${ }^{\circledR}$ oil was applied over the finished layer. The sliding interface between the prepared plinth surface and bond beam was provided with a layer of some durable material to facilitate sliding along the interface. The feasibility of this concept had been tested for sliding brick building models with different sliding layer materials, namely, graphite powder, dry sand, and wet sand. The friction coefficient values of these materials were obtained by sinusoidal shake table testing of models with the sliding joint. The coefficients of friction of different sliding materials were reported as: 0.25 for graphite powder, 0.34 for dry sand and 0.41 for wet sand. The cracks in specimen with sliding interface were observed to be much less than those in conventionally strengthened specimens. The use of sliding mechanism was found effective in preventing collapse of mud mortar specimens. A similar P-F isolation system had been proposed by $\mathrm{Li}$ [8] with specially screened sand layer in between terrazzo plate. The effectiveness of isolation system was tested by shake table tests. It was confirmed that the sliding begins when input acceleration exceeds a certain level, depending upon the coefficient of friction value of the sliding layer. The introduction of sliding joint in a masonry structure was also proposed by Zongjin et al. [9]. Three different sliding materials viz. derlin $(\mu=0.2)$, asphalt felt $(\mu=0.6)$ and vinyl flooring $(\mu=0.7)$ are used for a comparison study of isolation system. Lou et al. [22] have experimented with low friction materials as sliding joints to ensure building safety during strong earthquakes. Several brick with and without sliding joint were tested under lateral loads with simulated dead load. The walls with sliding joints were observed to slide at lateral force amplitude $50 \%$ of the force at which cracking begins in wall without sliding joint. Shaking table tests were also carried out with various sliding materials namely, graphite, screened gravel and paraffin wax. Sliding was reported to start on graphite/concrete interface $(\mu=0.23)$ at peak acceleration $0.2 \mathrm{~g}$ to $0.3 \mathrm{~g}$. A higher peak acceleration of $0.3 \mathrm{~g}$ to $0.6 \mathrm{~g}$ was reported to initiate slide on screened gravel/concrete interface $(\mu=0.4)$. Paraffin wax was not found suitable as sliding materials as its condensation cohesiveness led to rocking vibration before sliding. Tehrani and Hasani [5] conducted experimental studies with dune sand and lightweight expanded clay as sliding layers in adobe building in Iran. The coefficient of friction was reported as 0.25 for dune sand, 0.16 for clay, 0.2 to 0.3 for light expanded clay. They concluded that dune sand and lightweight expanded clay may be good material for creating sliding layer in adobe buildings in Iran. Nanda et al. $[15,16]$ conducted experimental studies with shake table test by providing geotextiles and smooth marble frictional base isolation system at plinth level of a brick masonry building. A $65 \%$ reduction in absolute response acceleration at the roof level was obtained in comparison with the response of the fixed base structure at the cost of $25 \mathrm{~mm}$ peak sliding displacement, which is well within plinth projection of $75 \mathrm{~mm}$ (3 in).

Song et al. [3] carried out tests for two six storey base isolated multi-storied brick masonry model on shake table. The isolation system composed of upper and lower reinforced concrete ring beams filled with two layers of asphalt felt interposed with graphite powder. The models had been tested on shake table with input peak acceleration varying from $0.1 \mathrm{~g}$ to $0.5 \mathrm{~g}$. It was observed that sliding starts at $0.25 \mathrm{~g}$ and no cracking in models was noticed even up to base acceleration of $0.5 \mathrm{~g}$. Nikolic-Brzev and Arya [19] reported an experimental study for seismic isolation of multi-storied masonry buildings. Multi-level isolation in the form of discrete isolation Teflon and stainless steel at base level and continuous isolation in the form of sliding joint at upper floor levels for multistory building were explored. An average reduction in maximum response accelerations and maximum base shear by around $30 \%$ and $40 \%$ respectively were obtained in isolated structure as compared to fixed base. 


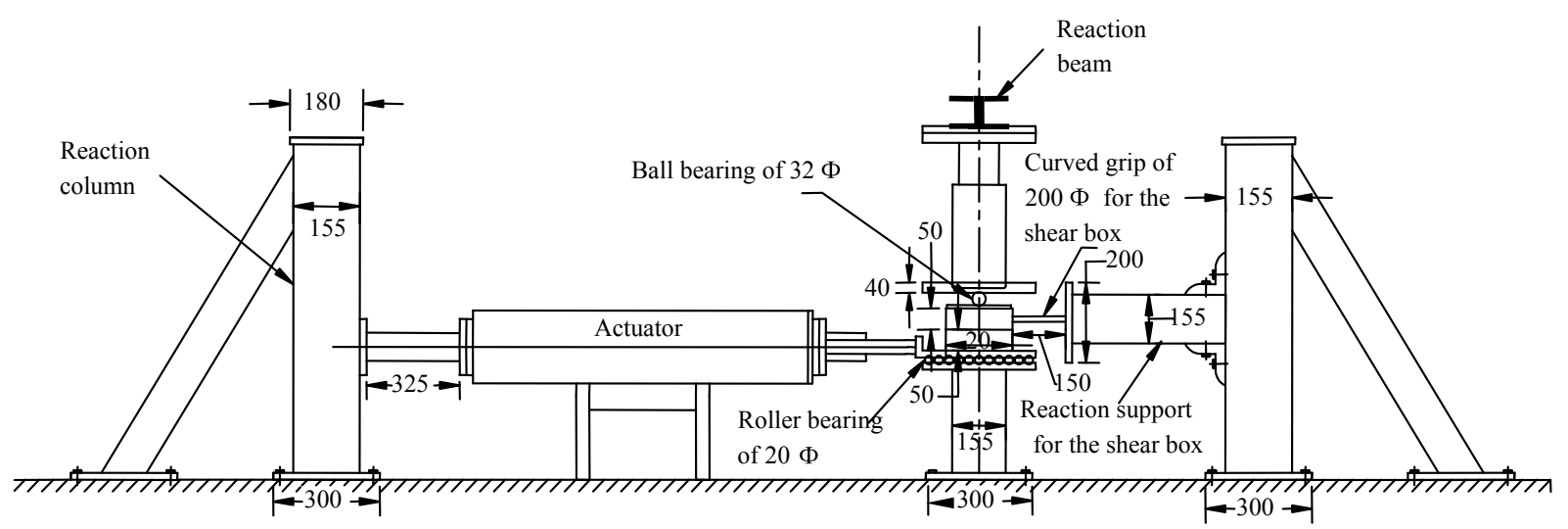

Fig. 1. Experimental set up for friction test with shear box (all dimensions are in $\mathrm{mm}$ ).

Previous studies on sliding isolation systems have primarily concentrated on the two dimensional planar base isolated models subjected to uni-directional excitation. These studies served to demonstrate the feasibility of P-F systems for mitigating the effects of earthquakes. A few others considered the effects of bi-directional excitation by two orthogonal ground motion components in horizontal plane [17,18]. It was shown that the bi-directional interaction increases the sliding displacement and decreases the acceleration of top mass. The effect of vertical component of earthquake ground motion can be easily accounted by considering an effective coefficient of friction $\mu^{\prime}=\mu\left(1+\ddot{\mathbf{z}}_{g} / g\right)$, where $\ddot{\mathrm{z}}_{g}$ denotes the vertical component of ground acceleration and $g$ is the acceleration due to gravity. The effect of vertical component on the acceleration response, however, has been reported to be negligible [14].

The implementation of seismic isolation for retrofitting of historic masonry buildings by friction isolation system without affecting the architecture has been reported by Mokha et al. [2], and Matsagar and Jangid [21]. Friction isolators are mounted by providing temporary supports along the masonry wall. Holes are created in the wall and a needle beam [21] supported over the seismic base isolators, is constructed progressively below the masonry wall. The temporary supports in the form of underpinning are then removed, thereby transferring the vertical load of the structure towards the foundation through the needle beam and the base isolators.

\section{Problem identification}

It has been observed in the above-mentioned studies that response of structure by P-F system is strongly dependent upon coefficient of friction for the sliding interface. The smaller the coefficient of friction the lesser is response acceleration and base shear. There is no restoring force provided by any type of external horizontal spring or damping elements. Lack of restoring force causes residual displacement at the sliding interface. Special attention needs to be given to keep these displacements within acceptable limits. Since a lower friction coefficient leads to larger sliding displacement, a usable range of friction coefficient has been suggested Nikolic-Brzev [20], which lies in the range (0.05-0.15). Previous investigations reveal that Teflon (PTFE) sliding against stainless steel gives very low friction value in the most desirable range i.e. 0.05 to 0.15 . For this reason Teflon has been utilized widely for more than 30 years in seismic isolators for bridges. However, a continuous bonding of steel sheet over concrete course is very expensive and leads to construction difficulties. Graphite, grease, screened sand, dry and wet sand are economical alternative but they can not be used for a long term as grease can be contaminated by debris, dirt, etc.; graphite can be affected by chemical reaction; and sand may get crushed after the shock which will increase the frictional resistance. Thus there is a need for search of alternative interface materials which may be easily available, economically viable and which can be readily adopted in construction. The present investigation is to explore alternative sliding interface materials for distributed base isolation by pure friction through an experimental and analytical study.

Four interfaces, namely, (i) green marble (smooth machine ground marble) /High Density Poly Ethylene (HDPE) ( $2 \mathrm{~mm}$ thick), (ii) green marble/green marble, (iii) green marble/geosynthetic (Non woven spun bonded $1.5 \mathrm{~mm}$ 


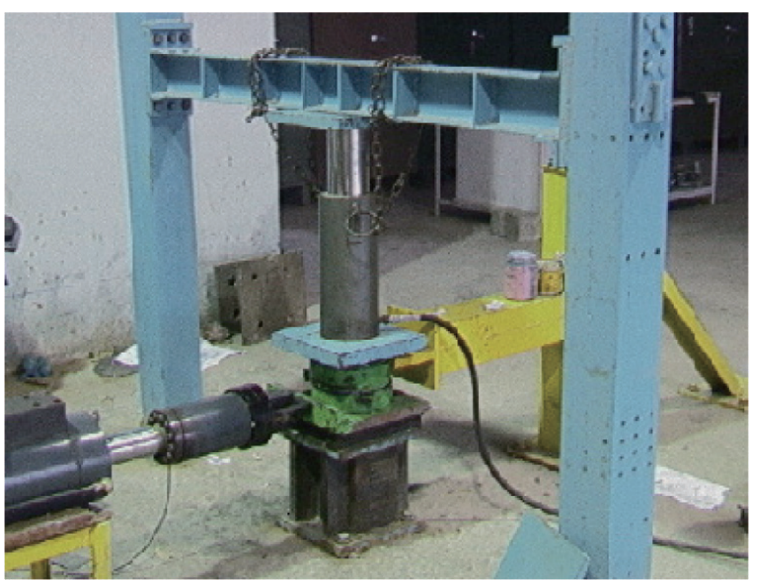

Fig. 2. Experimental set up for friction test with Shear Box (photographic view).

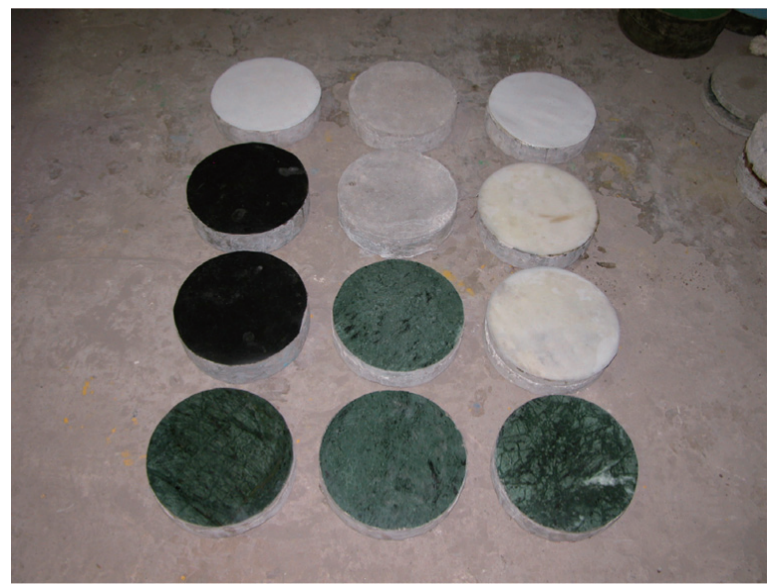

Fig. 3. Samples for friction test.

thick geotextile of brand Polyfelt TS-50), and (iv) green marble/rubber sheet (4 mm thick) have been studied in an experimental programme to test their efficiency for use as P-F isolation system. These materials are inexpensive, easily available in the market and can be easily bonded to building materials.

\section{Experimental study}

To obtain the optimum value of the coefficient of friction between different sliding interfaces under static and dynamic loading two types of experimental setups have been prepared. The setup consists of the large shear box test under static and dynamic loading condition as shown in Figs 1 and 2. The details of these tests are as follows:

\subsection{Shear box test}

The test setup mainly consists of three units: shear box unit, normal load unit and shear load unit. The shear box unit is in circular shape, consists of two halves each of $50 \mathrm{~mm}$ depth. It has been designed to accommodate samples of diameter $200 \mathrm{~mm}$. Upper half of the shear box is restrained against lateral movement, whereas the lower half of the shear box is free to move laterally. The lower half of the shear box rest on base plate and the whole assembly again rests on two trains of roller bearings of diameter $20 \mathrm{~mm}$. A foundation plate is also provided to support the shear box through steel column.

A groove is provided at the bottom plate to fix the shear box to the plate. The normal loading unit consists of a hydraulic jack and a reaction beam. The hydraulic jack can apply a maximum normal load of $250 \mathrm{kN}$ with a normal pressure of $8000 \mathrm{kN} / \mathrm{m}^{2}$ on the sample. The reaction beam is fixed to two vertical columns of size $700 \mathrm{~mm}$ $\times 700 \mathrm{~mm}$ through angles, which are firmly attached to the ground. The reaction beam is required to take up the normal reaction due to the vertical load applied by the hydraulic jack. To apply the normal load uniformly over the plane to be sheared, a top plate has been placed between the hydraulic jack and the sample. A ball bearing of $32 \mathrm{~mm}$ diameter has been provided between the top plate and the hydraulic jack to keep the vertical load in line. The arrangement is such that normal load passes through the centre of the shearing area. The shear load unit consists of a servo-controlled actuator to apply the horizontal load on test specimens.

\subsubsection{Friction test specimens}

Specimens of $200 \mathrm{~mm}$ diameter and $50 \mathrm{~mm}$ height (Fig. 3) were prepared in 1:1.5:3 concrete cast with smooth marble on one side. For different sliding couples, i.e., green marble/High Density Poly Ethylene (HDPE), green marble/geosynthetic and green marble/rubber, a HDPE sheet of $2 \mathrm{~mm}$ thickness, geosynthetic sheet of $1.5 \mathrm{~mm}$ thickness and natural rubber sheet of $4 \mathrm{~mm}$ thickness, respectively were pasted to smooth green marble by Bond Tite ${ }^{\circledR}$ adhesive. The specimens were kept in lower and upper shear box to permit sliding along the different sliding interfaces. 


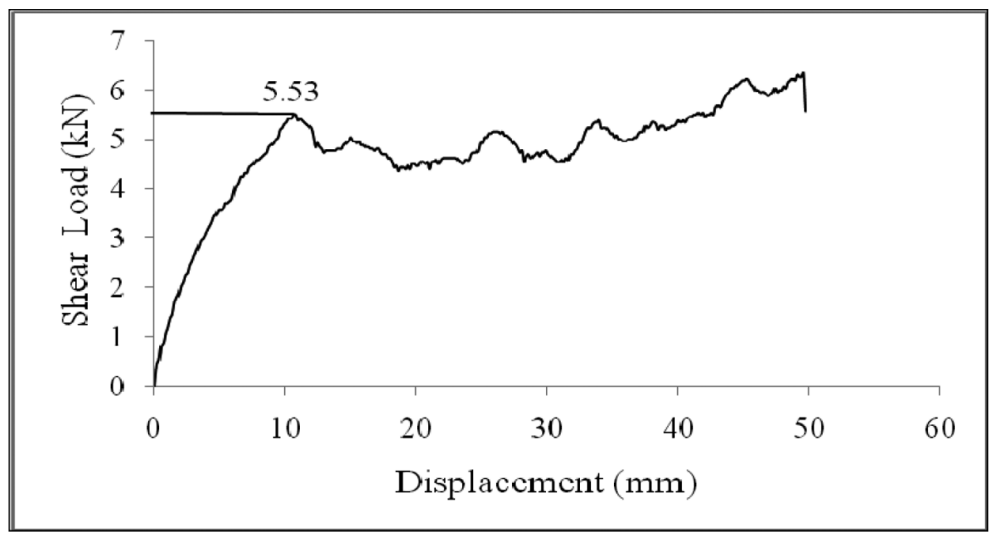

(a) Static Test

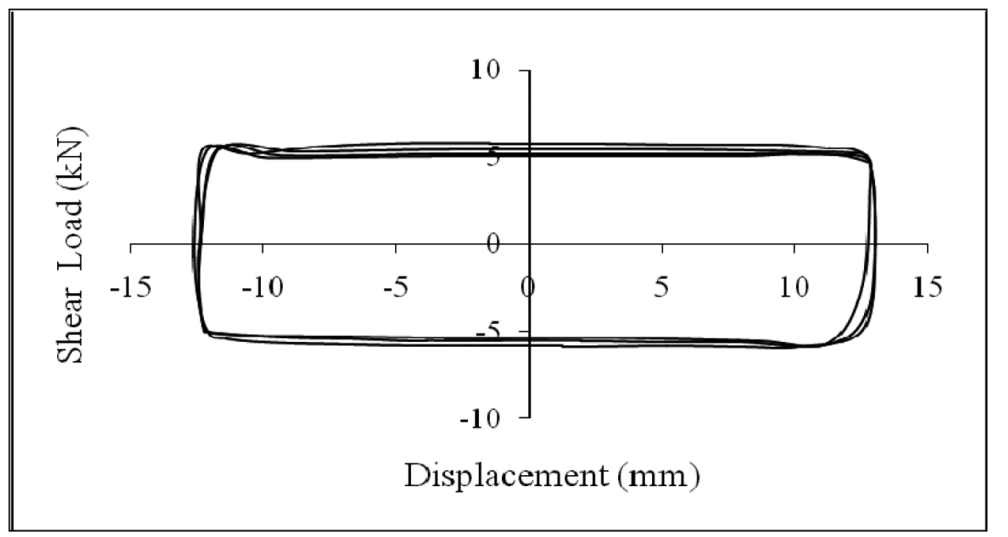

(b) Dynamic test $(12.5 \mathrm{~mm} / \mathrm{s})$

Fig. 4. Load-displacement graphs for static and dynamic test with $50 \mathrm{kN}$ normal load (green marble/geosynthetic).

\subsubsection{Static test}

Static tests were conducted under controlled displacement with the ramp rate held constant at $0.5 \mathrm{~mm} / \mathrm{s} \mathrm{with} \mathrm{ramp}$ limit of $25 \mathrm{~mm}$. For each combination the tests were carried with same and different samples with $10 \mathrm{kN}, 20 \mathrm{kN}$, and $50 \mathrm{kN}$ normal loads. Each test was repeated thrice to get the average value. Load and displacement data were obtained from the load cell and displacement transducer embedded in the servo control actuator of maximum shear load capacity of $100 \mathrm{kN}$ with stroke length of $300 \mathrm{~mm}$.

\subsubsection{Dynamic test}

Dynamic tests were carried out under displacement-controlled conditions at frequency of $0.25-1 \mathrm{~Hz}$ with ramp limit of $25 \mathrm{~mm}$ to give velocity of $12.5-50 \mathrm{~mm} / \mathrm{s}$. The tests were conducted on the same static test set up with a small modification. The top box was restrained in both directions while bottom shear box attached to the actuator was allowed to move in both directions. The samples were placed in the shear box; the normal load was applied through the vertical hydraulic jack and the horizontal cyclic loads of required frequencies were applied through the servo controlled actuator.

Figure 4 shows the load-displacement plots for static and dynamic test for a normal load of $50 \mathrm{kN}$ for green marble/geosynthetic interface. The coefficient of static friction from the static test was obtained as the ratio of the maximum shear force just before sliding to the normal load. The force-displacement hysteretic loops of sliding models in dynamic test, as shown in Fig. 4(b), are quite well formed and the dynamic friction coefficient was obtained as the ratio of the constant shear force sustained during the slip along the sliding interface to the normal force. From these tests, the average value of coefficient of static friction and dynamic friction for different interfaces 
Table 1

Coefficient of friction for different sliding interfaces

\begin{tabular}{|c|c|c|c|c|c|c|c|}
\hline \multirow[t]{2}{*}{ Interfaces } & \multicolumn{4}{|c|}{$\begin{array}{l}\text { Coefficient of static friction for } \\
\text { different normal loads }\end{array}$} & \multicolumn{3}{|c|}{$\begin{array}{l}\text { Coefficient of dynamic friction for dif- } \\
\text { ferent velocities }(50 \mathrm{kN} \text { normal load) }\end{array}$} \\
\hline & $10 \mathrm{kN}$ & $20 \mathrm{kN}$ & $50 \mathrm{kN}$ & Avg. & $12.5 \mathrm{~mm} / \mathrm{s}$ & $50 \mathrm{~mm} / \mathrm{s}$ & Avg. \\
\hline Green marble/HDPE & 0.08 & 0.07 & 0.09 & 0.08 & 0.07 & 0.07 & 0.07 \\
\hline Green marble /green marble & 0.08 & 0.09 & 0.09 & 0.09 & 0.09 & 0.08 & 0.08 \\
\hline Green marble / geosynthetic & 0.11 & 0.11 & 0.11 & 0.11 & 0.10 & 0.10 & 0.10 \\
\hline Green marble/rubber & 0.17 & 0.16 & 0.16 & 0.16 & 0.20 & 0.17 & 0.18 \\
\hline
\end{tabular}

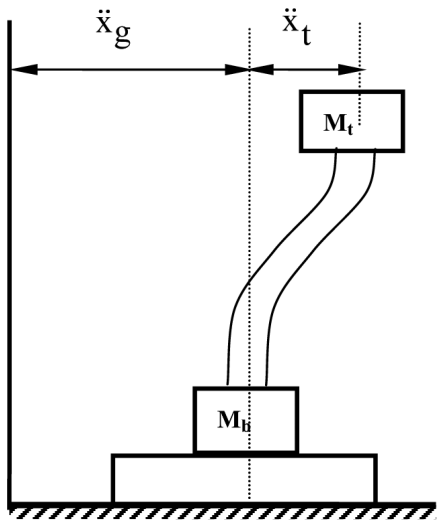

Non-Sliding

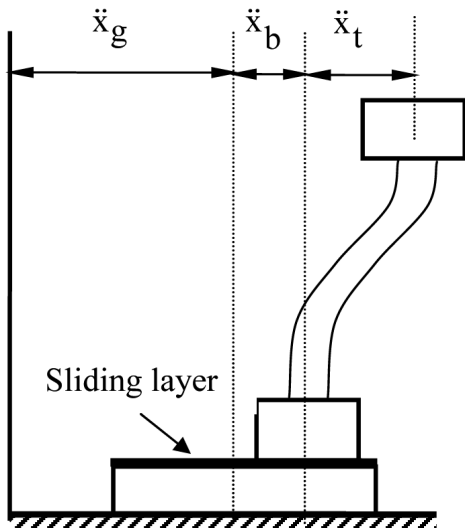

Sliding

Fig. 5. Mathematical model for system with a non-sliding and sliding mode.

are shown in Table 1. No significant variation was also observed in the coefficient of static friction for the range of normal loads considered and the coefficient of dynamic friction were found to be insensitive to the velocity variations $(12.5-50 \mathrm{~mm} / \mathrm{sec})$. The observed dynamic coefficient of friction is slightly smaller than the static coefficient of friction and may be assumed identical for all practical purposes. All the tests were carried at $35^{\circ} \mathrm{C}$. No wearing or tearing was observed after each test while in a few cases there was an opening of bonding. In that case new materials were again pasted with the samples by adhesive. Even after $50 \mathrm{kN}$ load test which is equivalent to 3 storeys load at the base there was no signs of melting of rubber. The shear box test reveal that sliding couples made up of green marble/HDPE, green marble/green marble, green marble/geosynthetic give coefficient of friction values in the desirable range.

\section{Analytical modeling}

The coefficients of frictions for different interfaces are used in the analytical calculation for finding the structural responses. A two-mass model, as shown in Fig. 5, is used to describe the seismic behavior of a single storey building with a sliding interface $[4,12]$. The structure above the sliding joint is assumed to remain elastic as the purpose of base isolation is to reduce the earthquake forces in such a way that the system remains within elastic limit. The mass of the roof in addition to one half the mass of the wall is lumped at the roof $\left(M_{t}\right)$ while the rest is lumped at the base with the mass of the bond beam $\left(M_{b}\right)$. The base mass is assumed to rest on a plane with dry friction damping of coulomb type to permit sliding of the system.

Let the ground acceleration be denoted by $\ddot{x}_{g} ; x_{t}$ and $x_{b}$ represent the relative displacement of top mass with respect to bottom mass and relative displacement of the bottom mass with respect to ground respectively; and $\theta\left(=M_{t} / M_{b}\right)$ be the mass ratio (MR). The natural frequency of the non-sliding system $\left(\omega_{n}\right)$ is related to the stiffness $(K)$ and the top mass as $\omega_{n}=\sqrt{K / M_{t}}$, and $\xi\left(=C / 2 \omega_{n} M_{t}\right)$ is the fraction of critical damping, where $C$ is the damping coefficient. 


\subsection{Non-sliding condition}

The governing differential equation for non-sliding condition can be obtained from equilibrium considerations as:

$$
M_{t}\left(\ddot{x}_{g}+\ddot{x}_{t}\right)+C \dot{x}_{t}+K x_{t}=0
$$

which may be rearranged as:

$$
\ddot{x}_{t}+2 \xi \omega_{n} \dot{x}_{t}+\omega_{n}^{2} x_{t}=-\ddot{x}_{g}
$$

The above equation governing the dynamic response of the system to base excitation during non-sliding condition is exactly same as that for a fixed base system.

\subsection{Sliding condition}

The sliding of bottom mass begins when the sliding force overcomes the frictional resistance at the plinth level. The building now acts as two degree of freedom system and governing differential equation of motion of top mass can be derived from equilibrium considerations:

$$
M_{t}\left(\ddot{x}_{g}+\ddot{x}_{b}+\ddot{x}_{t}\right)+C \dot{x}_{t}+K x_{t}=0
$$

which can be simplified as:

$$
\ddot{x}_{t}+\ddot{x}_{b}+2 \xi \omega_{n} \dot{x}_{t}+\omega_{n}^{2} x_{t}=-\ddot{x}_{g}
$$

while the motion of the bottom mass may be described by:

$$
M_{b}\left(\ddot{x}_{g}+\ddot{x}_{b}\right)-C \dot{x}_{t}-K x_{t}+\mu\left(M_{t}+M_{b}\right) g \operatorname{sgn}\left(\dot{x}_{b}\right)=0
$$

which may be rearranged as:

$$
\ddot{x}_{b}-2 \xi \omega_{n} \theta \dot{x}_{t}-\omega_{n}^{2} \theta x_{t}+\mu(1+\theta) g \operatorname{sgn}\left(\dot{x}_{b}\right)=-\ddot{x}_{g}
$$

where, $\operatorname{sgn}(x)=\left\{\begin{array}{c}1, x>0 \\ -1, x<0\end{array}\right.$ denotes the signum function.

The non-sliding condition prevails when the horizontal inertia force of bottom mass does not exceed the opposing friction force at plinth level, i.e.

$$
\left|C \dot{x}_{t}+K x_{t}-M_{b}\left(\ddot{x}_{g}+\ddot{x}_{b}\right)\right|<\mu\left(M_{t}+M_{b}\right) g
$$

or,

$$
\left|2 \xi \omega_{n} \dot{x}_{t}+\omega_{n}^{2} x_{t}-\left(\ddot{x}_{g}+\ddot{x}_{b}\right) / \theta\right|<\mu(1+1 / \theta) g
$$

As long as the dynamic lateral force does not exceed the frictional resistance at the sliding interface, there is no relative movement between the bottom mass and the base/ground, i.e. $x_{b}=0$. The sliding initiates whenever the force acting at the base exceeds the frictional resistance and stops whenever the non-slip condition (Eq. (4)) holds. Thus at any time instant response of the building can be obtained by solving either Eq. (1) when the non-sliding condition (Eq. (4)) holds, or two coupled differential equations (Eqs (2) and (3)) during the sliding phase. These equations are solved by using Runge-Kutta 4th order solver in MATLAB-SIMULINK environment. It may be noted that this analytical model describes both possible ways of implementing frictional isolation, namely, the base isolation and the foundation isolation. The parameter of the analytical model that captures the difference between these two possible isolation systems is the mass ratio $(\theta)$. For a typical building on a sliding interface, the base isolation at plinth level corresponds to a higher mass ratio while the mass ratio decreases for foundation isolation systems as the weight of the sliding base increases substantially. It has been reported that for a given sliding interface, the energy dissipation at the frictional interface is greater for systems with higher mass ratio [12]. Moreover, the response of sliding system can sometimes exceed that of fixed base system for small mass ratios [4]. Therefore, it appears that base isolation systems should be the preferred mode of implementing sliding interfaces, at least for rural dwellings, which do not have many service pipelines vulnerable to the sliding displacements during an earthquake. 

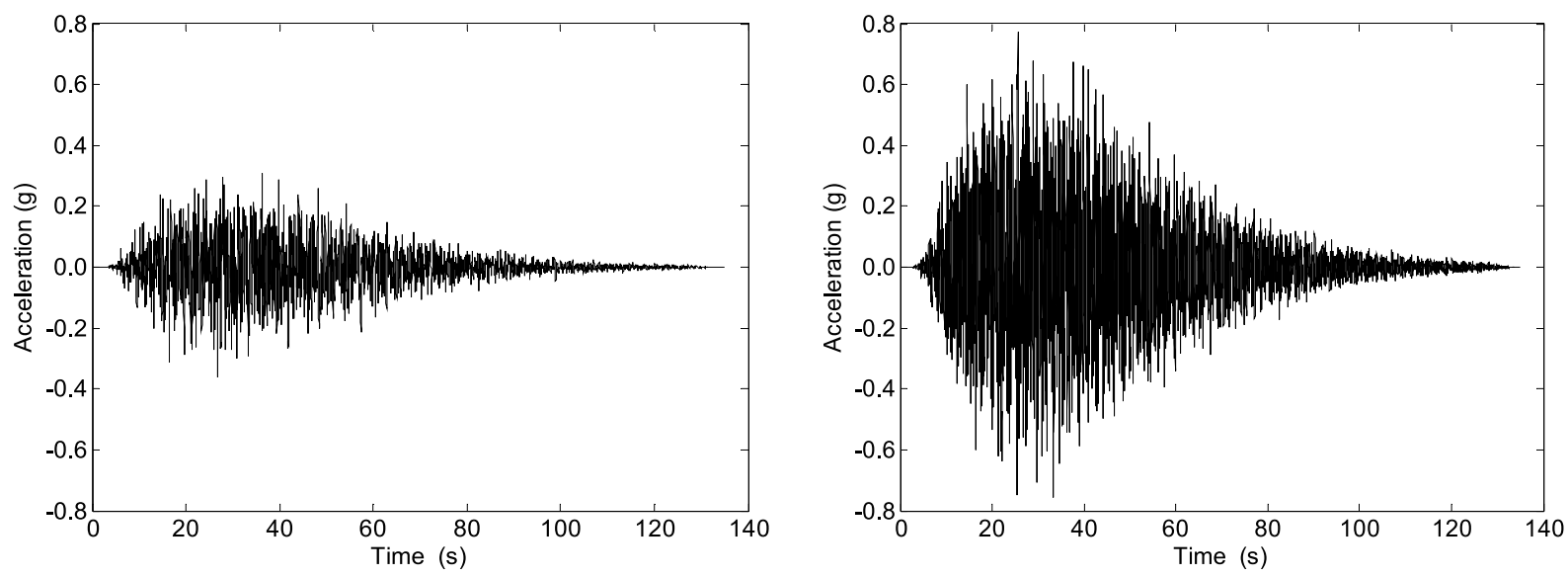

Fig. 6. Spectrum compatible ground motion (left) and corresponding absolute acceleration response of roof mass (right) for fixed building.

\section{Results and discussion}

The effect of the ground motion on the behaviour of proposed isolation system is investigated analytically by using a synthetic accelerogram that is compatible with the design spectrum of Indian standard, IS 1893 (Part 1): 2002 [6] corresponding to the level of maximum considered earthquake in the most severe seismic zone $(\mathrm{PGA}=0.36 \mathrm{~g})$. Figure 6 shows the spectrum compatible ground motion (with $0.36 \mathrm{~g} \mathrm{PGA}$ ) and the computed absolute acceleration response at roof level for fixed structure and Fig. 7 shows absolute acceleration response of roof mass for different types of sliding interfaces single storey buildings of mass ratio (MR) 2, time period $\left(T_{n}\right) 0.1 \mathrm{~s}$ and damping $(\xi) 5 \%$ critical. In case of fixed-base building there is $100 \%$ amplification in the peak acceleration response $(\sim 0.8 \mathrm{~g})$.

The peak absolute acceleration at roof level is $0.3 \mathrm{~g}, 0.35 \mathrm{~g}, 0.4 \mathrm{~g}$ and $0.6 \mathrm{~g}$ for sliding couples green marble/HDPE, green marble/green marble, green marble/geosynthetic, green marble/rubber respectively. This confirms that with the lower value of friction coefficient, the acceleration amplification is also lower. Figure 8 shows relative displacement response for different sliding combinations. An increase in the sliding displacement is observed with decreasing coefficients of friction.

Figure 9(a) shows Smooth Fourier amplitude spectra of ground acceleration (left) and corresponding absolute response acceleration of roof mass (right) of fixed base building while Fig. 9(b) represents Smooth Fourier amplitude spectra of absolute response acceleration of roof mass for different sliding interfaces buildings for a single storey building of mass ratio (MR) 2, time period $\left(T_{n}\right) 0.1 \mathrm{~s}$ and damping $(\xi) 5 \%$ critical. The Fourier amplitude amplified in case of fixed base structure while for sliding base structures the amplitudes reduces as the coefficient of friction decreases and is least for green marble/HDPE interface.

Figures 10 and 11 show acceleration response spectra at roof and relative displacement spectra at base level for fixed and different sliding interfaces, respectively. The spectral acceleration is greatly reduced for sliding interfaces of green marble/geosynthetic, green marble/green marble and green marble/HDPE due to friction. With the decrease in coefficient of friction, the amplification of the spectral acceleration tends to be insensitive to the natural period of the super-structure and the absolute acceleration spectrum is almost flat over the whole range of natural periods. The maximum reduction in spectral acceleration is observed in case of green marble and HDPE interface at the cost of increased sliding displacement at plinth level. Hence green marble and geosynthetic are better and alternatives for use in P-F isolation system with equal effectiveness for energy dissipation and also for limiting the earthquake energy transmission to superstructure during strong earthquake which leads to a low cost, durable solution for earthquake protection of masonry buildings. In general, smaller the coefficient of friction, higher is the spectral displacement response but the spectral displacement is within $50 \mathrm{~mm}$ in all cases for short period structures, i.e., $T_{n}<0.2 \mathrm{~s}$. It is worth noting that most masonry buildings are stiff structures with time period less than $0.2 \mathrm{~s}$ and the sliding displacements would be within the usual plinth projection of $75 \mathrm{~mm}$ (3 in).

The behavior of masonry building with sliding interface without green marble/rubber interface (as friction coefficient is not in the suitable range) has also been studied for a set of two near-field real earthquake ground motions, namely: 

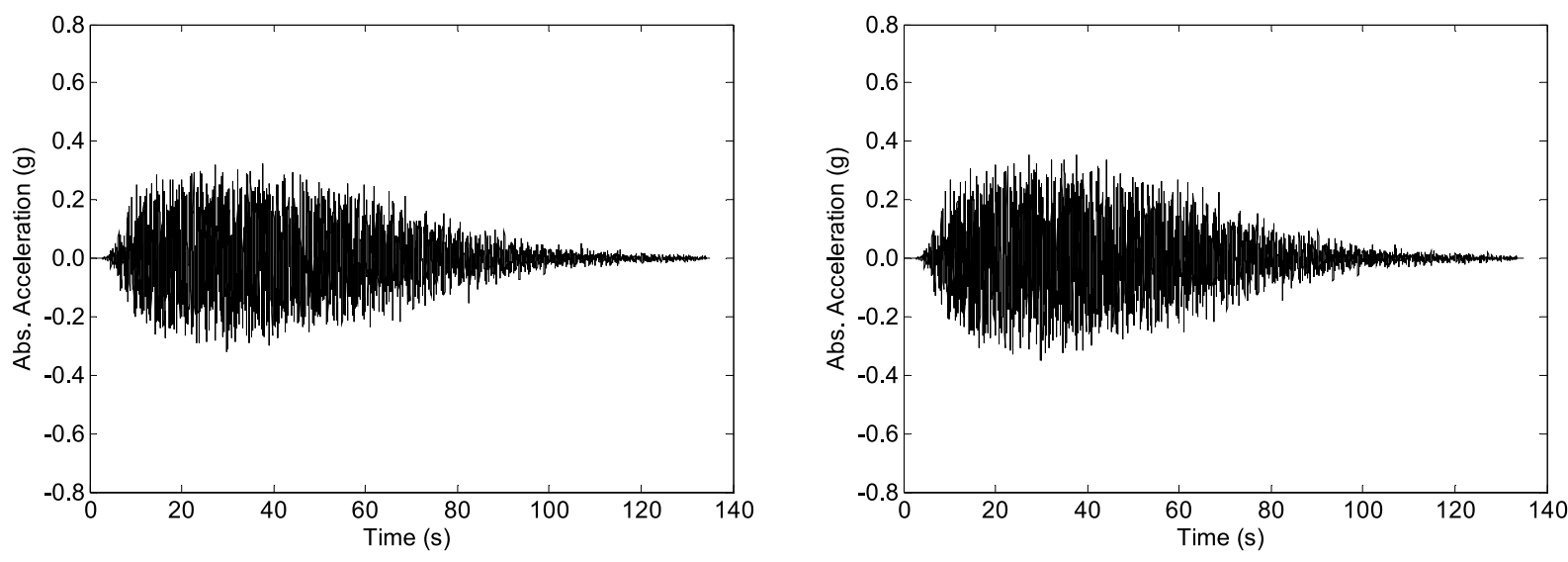

Green marble/HDPE
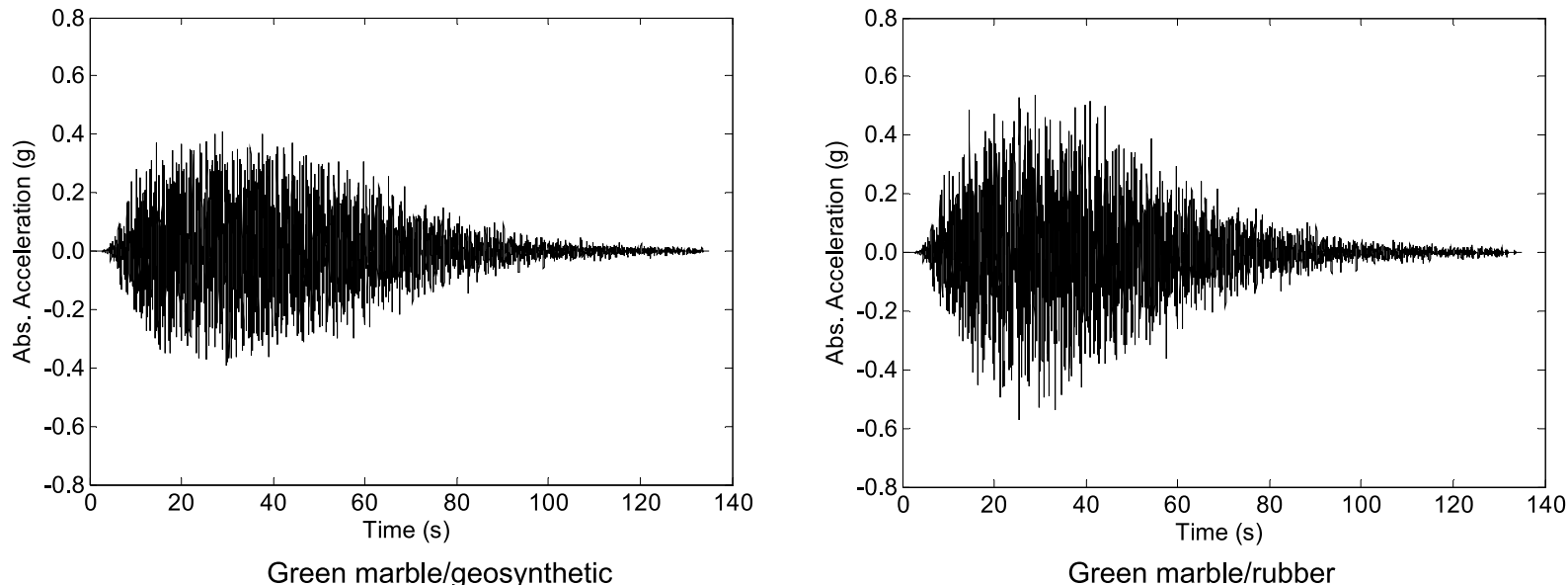

Fig. 7. Absolute acceleration response of roof mass for different sliding interfaces buildings.

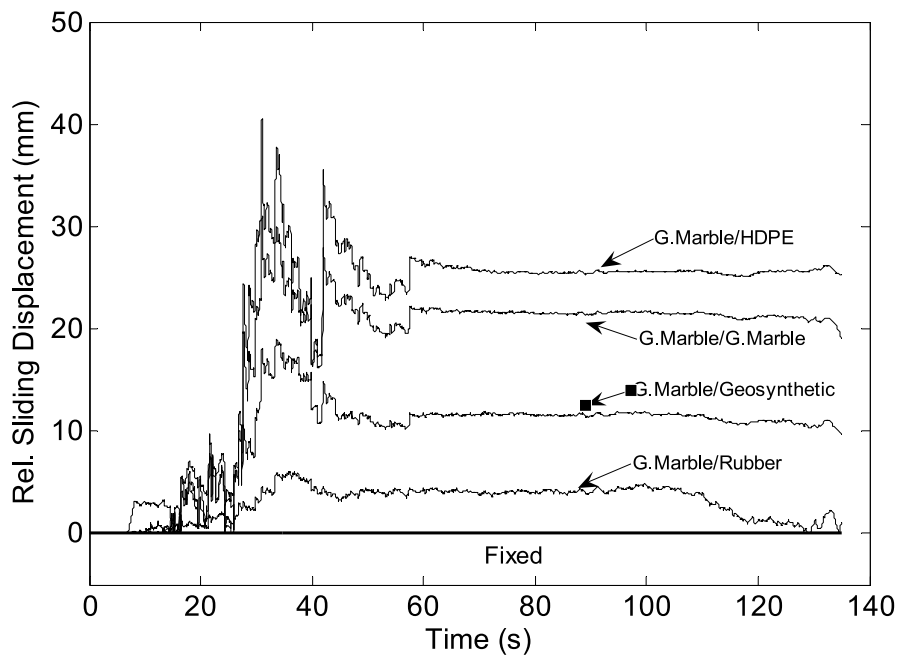

Fig. 8. Relative sliding displacement response for different sliding interfaces. 

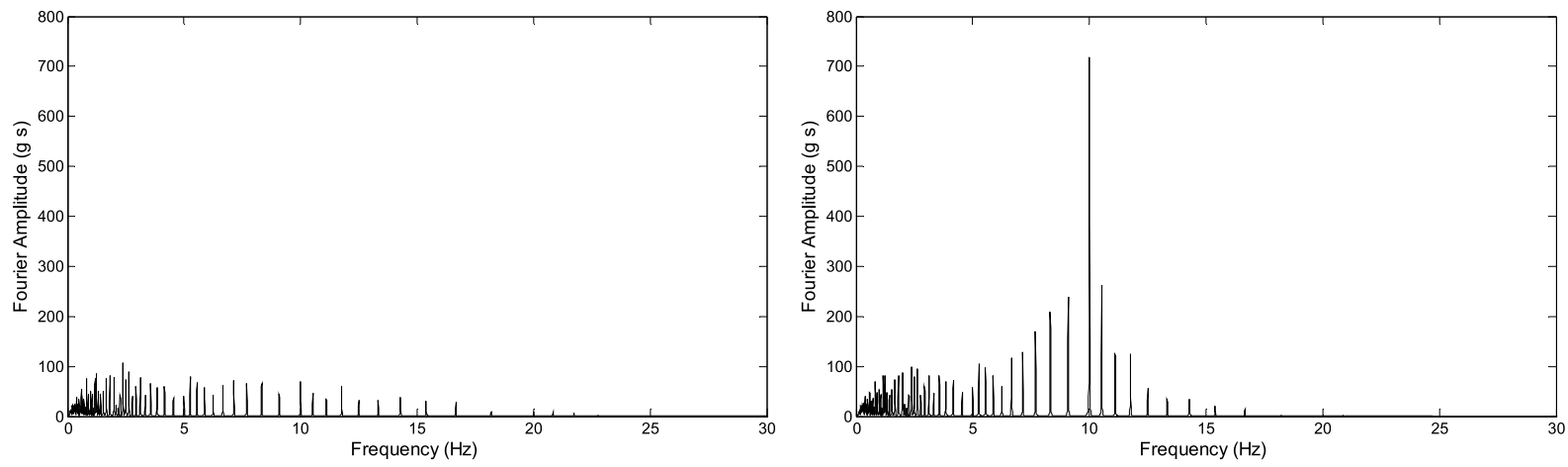

(a)
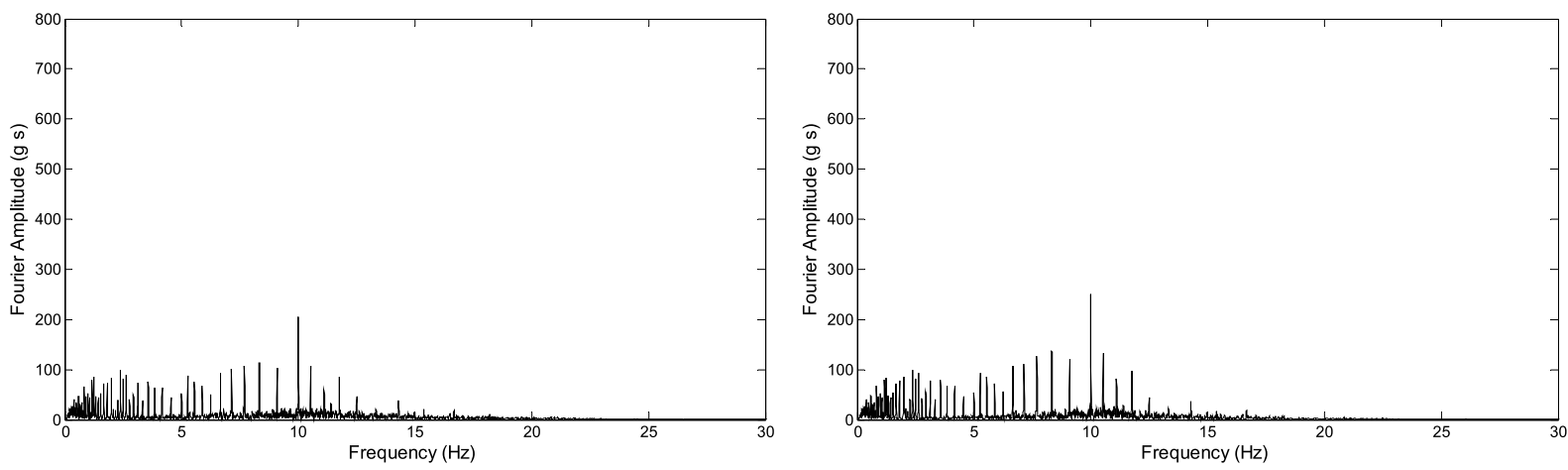

Green marble/HDPE

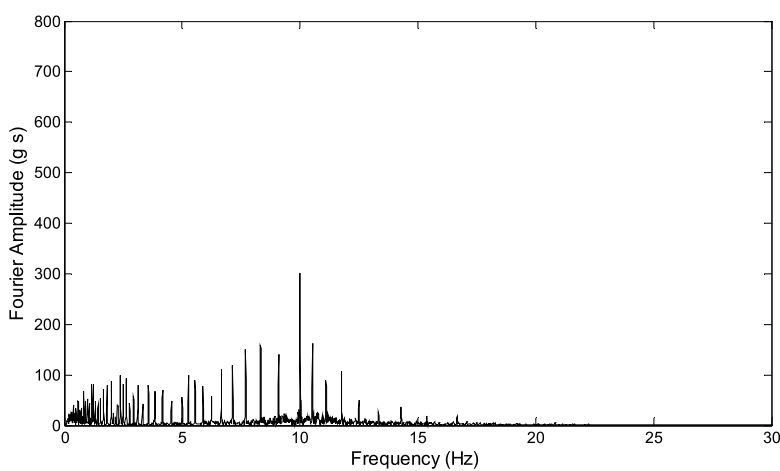

Green marble/green marble

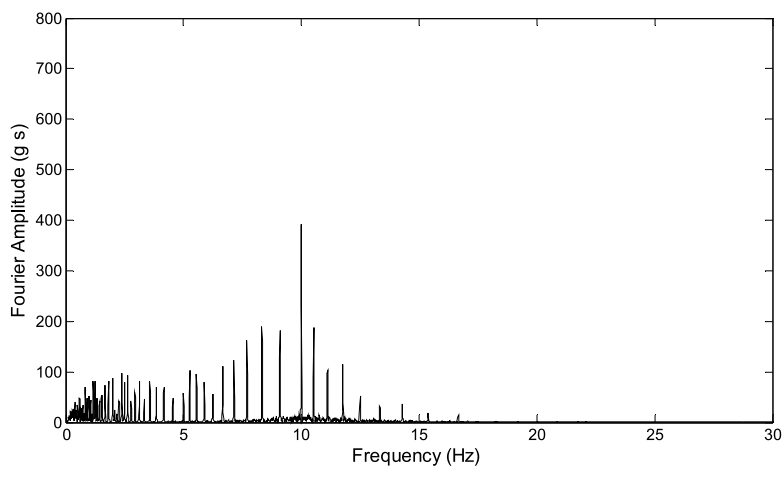

Green marble/geosynthetic

Green marble/rubber

(b)

Fig. 9. a) Smooth Fourier amplitude spectra of ground acceleration (left) and corresponding absolute response acceleration of roof mass (right) of fixed base building. b) Smooth Fourier amplitude spectra of absolute response acceleration of roof mass for different sliding interfaces buildings.

1. The 28 June 1992 Landers earthquake recorded at Joshua Tree, CA, Fire Station (CSMIP station 22170) $10 \mathrm{~km}$ from the fault, Component: 90, with $0.28 \mathrm{~g}$ PGA.

2. The 20 September 1999 Chi-Chi earthquake recorded at CWB station TCU078, $8.3 \mathrm{~km}$ from the fault, Component: 90, with 0.44 g PGA.

The response of the sliding system (Figs 12 and 13) for all these real earthquake motions is along the similar lines as shown for the case of spectrum compatible motion. The maximum relative displacement along the sliding interface is less than $50 \mathrm{~mm}$ for all motions and a very small amplification (over the PGA level) in the absolute 


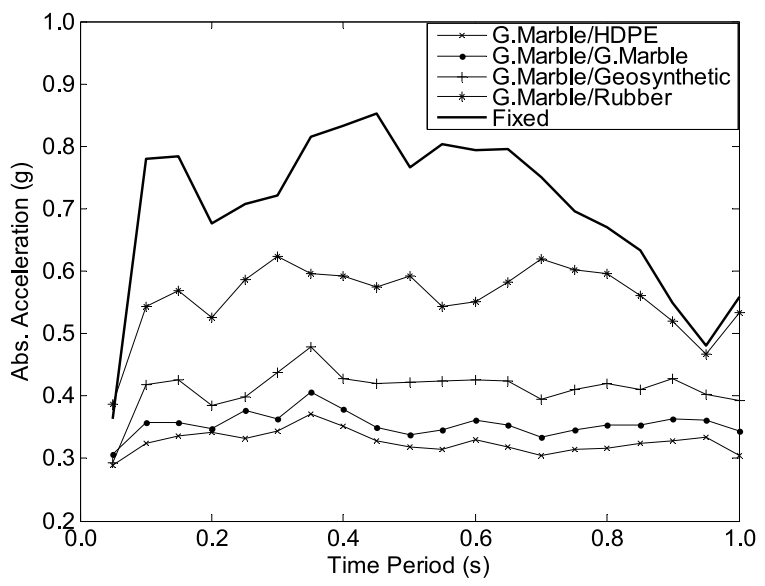

Fig. 10. Absolute acceleration spectra of the roof mass for fixed and different sliding interfaces for spectrum compatible ground motion.

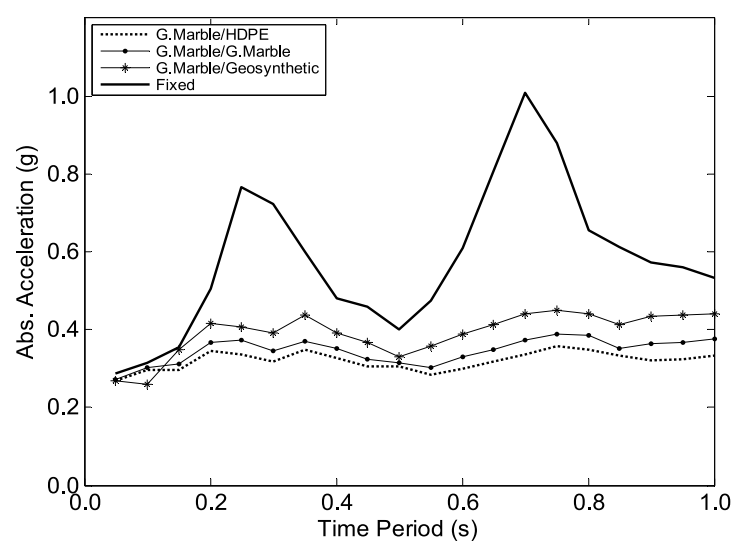

(a)

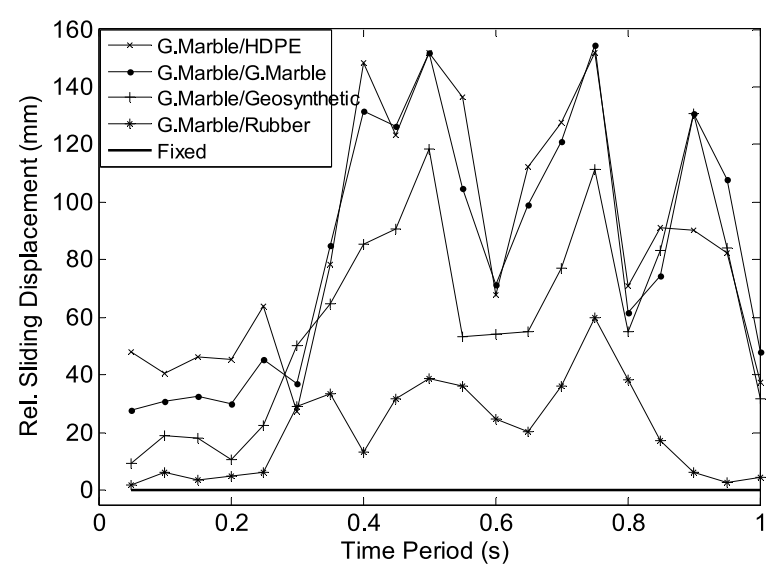

Fig. 11. Displacement spectra for fixed and different sliding interfaces for spectrum compatible ground motion.

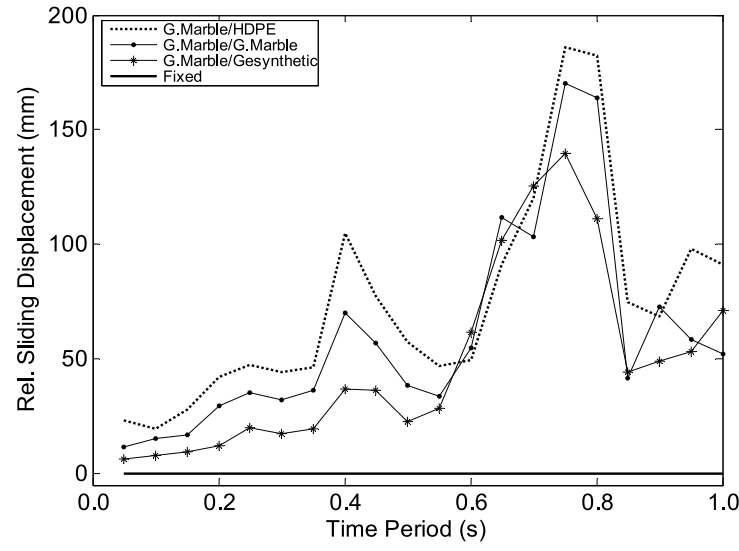

(b)

Fig. 12. a) Absolute acceleration spectra of the roof mass and b) relative displacement spectra of the bottom mass for different sliding interfaces for Landers 1992 earthquake.

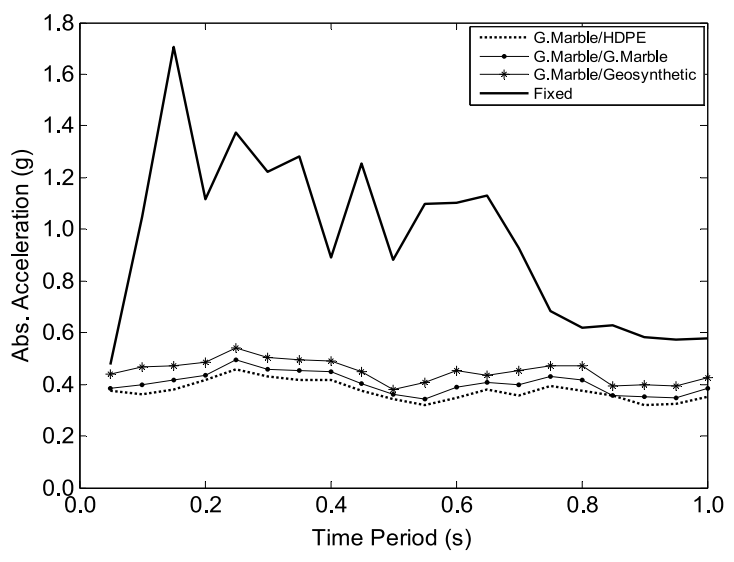

(a)

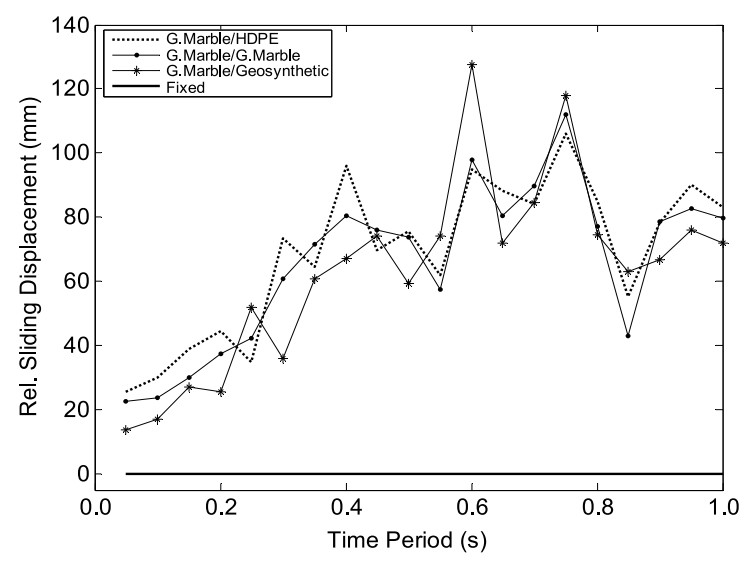

(b)

Fig. 13. a) Absolute acceleration spectra of the roof mass and b) relative displacement spectra of the bottom mass for different sliding interfaces for Chi-Chi earthquake 1999. 
acceleration response at roof level of the building on sliding interface.

Teflon-stainless steel sliding couples used in bridge bearings are of discrete type, circular or square in shape. Distributed isolators in the form of long strips would have distinct advantages over square or circular isolator bearings when applied to masonry brick buildings where the lateral-resisting system comprises of walls. Additional horizontal frames of girders are needed to transmit the weight of building through these bearing. This requires extra labour and materials which leads to additional cost. In Indian market distributed isolator in the form of stainless steel $(1 \mathrm{~mm}) /$ Teflon $(2 \mathrm{~mm})$ sliding couples for the proposed masonry buildings cost $800 \mathrm{INR}$ (20 \$US) per meter run approximately, which requires higher seating width and additional spikes arrangement for fixing with masonry walls while the approximate cost is 250 INR (6 \$US) and 200 INR (5 \$US) per meter run for the proposed best sliding couples viz. green marble/green marble and green marble/geosynthetic, which can be easily bonded with building materials and can be used by the rural population easily.

\section{Conclusions}

The friction tests reveal that sliding couples made of green marble/HDPE, green marble/green marble, and green marble/geosynthetic exhibit coefficient of friction value in the desirable range i.e. 0.05 to 0.15 with least for green marble/HDPE. Analytical modeling and calculation show that these sliding materials allows the superstructure to slide with equal effectiveness of earlier investigated materials such as graphite, screened gravel, dune sand, Teflonsteel, clay, fine sand-terrazzo plates, which have not received wide acceptance as a material for rural constructions because of their high costs, construction complications, and/or low durability. These interface materials are more durable and are least affected by environment. The spectral acceleration is greatly reduced for sliding interfaces of green marble/geosynthetic, green marble/green marble and green marble/HDPE with maximum reduction in case of green marble and HDPE interface at the cost of increased sliding displacement at plinth level. It is found that spectral displacement is within $50 \mathrm{~mm}$ for short period structure, i.e., $T_{n}<0.2 \mathrm{~s}$. As most brick masonry buildings are stiff with period less than $0.2 \mathrm{~s}$, the sliding displacements are within plinth projection of $75 \mathrm{~mm}(3 \mathrm{in})$. Hence green marble and geosynthetic are better and alternatives for use in P-F isolation system with equal effectiveness for energy dissipation and also for limiting the earthquake energy transmission to superstructure during strong earthquake which leads to a low cost, durable solution for earthquake protection of masonry buildings. The cost of providing green marble/green marble interface and green marble/geosynthetic works out to approximately 250 INR (6 \$US) and 200 INR (5 \$US) per meter run respectively in India as against 800 INR (20 \$US) per meter run for the case of Teflon/stainless steel interface, which is commonly used for bridge bearings.

\section{References}

[1] A.S. Arya, Sliding concept for mitigation of earthquake disaster to masonry buildings, Proceedings of 8th World Conference on Earthquake Engineering, San Francisco, 5 (1984), 951-958.

[2] A.S. Mokha, N. Amin, M.C. Constantinou and V. Zayas, Seismic isolation retrofit of large historic building, ASCE Journal of Structural Engineering 122(3) (1996), 298-308.

[3] B. Song, C. Yin, X. Zhang and S. Tao, Experimental study and seismic response analysis of multi-storeyed brick buildings with friction base isolation, Proceedings 5th North America Masonry Conference, Univ. of Illinois, Urbana-Champaign, 1990, 77-787.

[4] B. Westermo and F. Udwadia, Periodic response of a sliding oscillator system to harmonic excitation, Earthquake Engineering and Structural Dynamics 11(1) (1983), 135-146.

[5] F.M. Tehrani and A. Hasani, Behaviour of Iranian low rise buildings on sliding base to earthquake excitation, Proceedings of 11th World Conference on Earthquake Engineering, Mexico City, Mexico, 1996, Paper 1433.

[6] IS: 1893 (Part 1): Criteria for earthquake resistant design of buildings, Bureau of Indian Standard, New Delhi, 2002.

[7] J.A. Calantarients, Improvements in and connected with building and other works and appurtenances to resist the action of earthquakes and the like, Engineering Library, Stanford University, Stanford, California, 1909, Paper No. 325371.

[8] L. Li, Base isolation measure for aseismic buildings in China, Proceedings of 8th World Conference on Earthquake Engineering, San Francisco, 6 (1984), 791-798.

[9] L. Zongjin, E.C. Rossow and S.P. Shah, Sinusoidal forced vibration of sliding masonry system, ASCE Journal of Structural Engineering 115(7) (1989), 1741-1755.

[10] M. Qamaruddin, A.S. Arya and B. Chandra, Seismic response of masonry buildings with sliding substructure, ASCE Journal of Structural Engineering 3 (1986), 558-572. 
[11] M. Sassu, The reinforced cut wall (rcw): a low-cost base dissipator for masonry buildings, Earthquake Spectra 22(2) (2006), 533-554.

[12] N. Mostaghel and J. Tanbakuchi, Response of sliding structures to earthquake support motion, Earthquake Engineering and Structural Dynamics 11(6) (1983), 729-748.

[13] P. Agarwal and M. Shrikhande, Earthquake resistant design of structures, PHI Learning Pvt. Ltd., New Delhi, India, 2006.

[14] P. Tsopelas, M.C. Constantinou, Y.S. Kim and S. Okamoto, Experimental study of FPS system in bridge seismic isolation, Earthquake Engineering and Structural Dynamics 25(1) (1996), 65-78.

[15] R.P. Nanda, P. Agarwal and M. Shrikhande, Earthquake hazard mitigation for rural dwellings by P-F base isolation; Proceedings of 14th World Conference on Earthquake Engineering, Beijing, 2008, Paper id-09-02-0017.

[16] R.P. Nanda, P. Agarwal and M. Shrikhande, Frictional base isolation by geotextiles for brick masonry buildings, Geosynthetic International 17(1) (2010), 48-55.

[17] R.S. Jangid, Response of pure friction sliding structures to bi-directional harmonic ground motion, Journal of Engineering Structures 19(2) (1997), 97-104.

[18] S. Ahmad, M. Qamaruddin, H. Irtaza and M.Z. Islam, Response of multi story masonry building with sliding substructure subjected to bi-directional earthquake ground motions, Proceedings of 13th World Conference on Earthquake Engineering, Vancouver, Canada, 2004, Paper No. 236.

[19] S. Nikolic-Brzev and A.S. Arya, Seismic isolation of masonry buildings-an experimental study, Proceedings of 11th World Conference on Earthquake Engineering, Mexico, 1996, Paper 1338.

[20] S. Nikolic-Brzev, Seismic protection of multi-storey brick buildings by seismic isolation technique, Ph.D Thesis, Department of Earthquake Engineering, University of Roorkee, Roorkee, 1993.

[21] V.A. Matsagar and R.S. Jangid, Base isolation for seismic retrofitting of structures, ASCE Practice Periodical on Structural Design and Construction 13(4) (2008), 175-185.

[22] Y. Lou, M. Wang and J. Su, A research of sliding shock absorbing multi-storeyed brick buildings, Proceedings of 10th World Conference on Earthquake Engineering, Barcelona, Spain, 4 (1992), 2499-2503. 

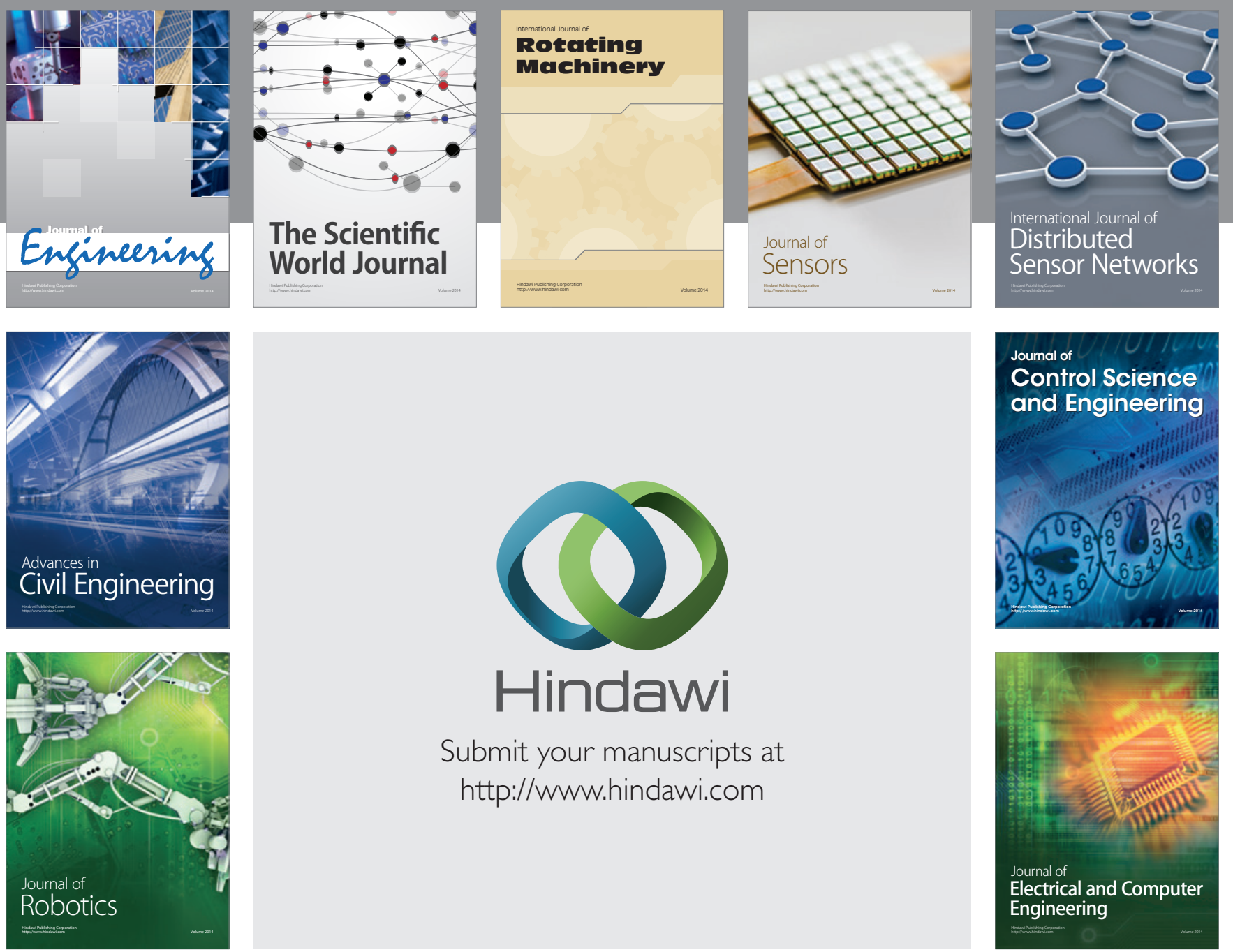

Submit your manuscripts at

http://www.hindawi.com
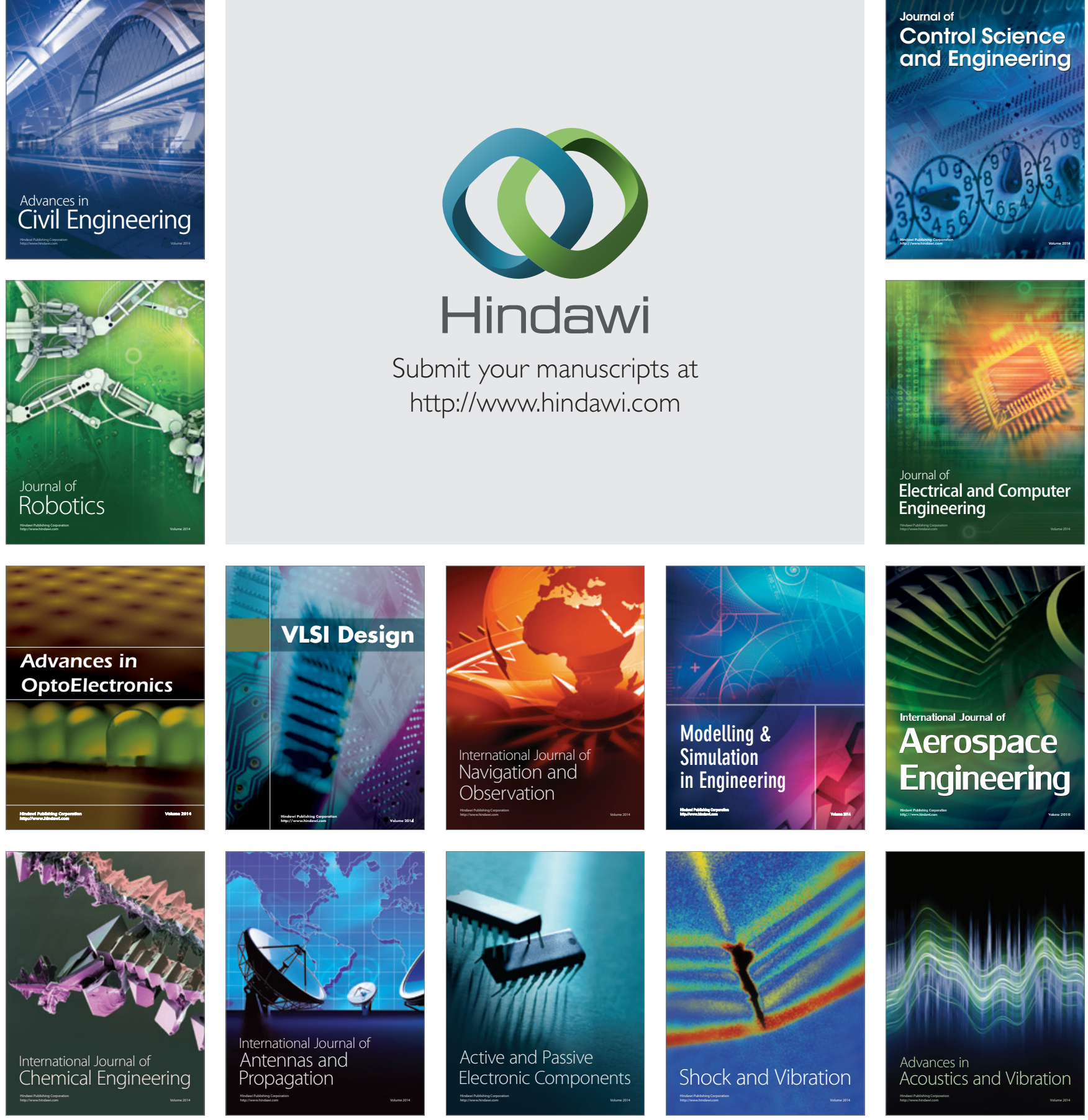